\title{
BLICKDIAGNOSE-QUIZ
}

Zufallsbefund an der Hand

\section{Ein rudimentärer Finger?}

\section{Auflösung von Seite 9}

- Bei dem Befund handelt es sich um ein Ganglion, im Laienjargon auch Überbein genannt. Es ist die häufigste Tumorbildung an der Hand. Meist findet man es am Handgelenk, seltener am Handrücken und auf den Beugeseiten. Gelegentlich sind aber auch die Finger betroffen, vor allem in der Grundgelenkbeugefalte und am Endgelenk auf der Streckseite.

Beim Ganglion handelt es sich um eine gutartige, mit gallertartiger Flüssigkeit gefüllte, prall elastische Geschwulstbildung infolge Ausstülpung der Gelenkkapsel bzw. des Sehnenscheidengewebes. Somit ist es keine Knochenveränderung, sodass der Begriff "Überbein" nicht gerechtfertigt ist.
Eine Ursache für die Entstehung eines solchen Ganglions findet sich meist nicht. Es tritt jedoch häufig bei chronischer Überlastung, plötzlicher Drucksteigerung im Gelenk z. B. nach einem Sturz oder bei degenerativen Gelenkerkrankungen auf. Die einzige sinnvolle Therapie ist die operative Entfernung.

\section{Keyword: ganglion}

- Dr. med. P. Stiefelhagen,Westerwald-Klinik Hachenburg, Alte Frankfurter Straße 12, D-57627 Hachenburg

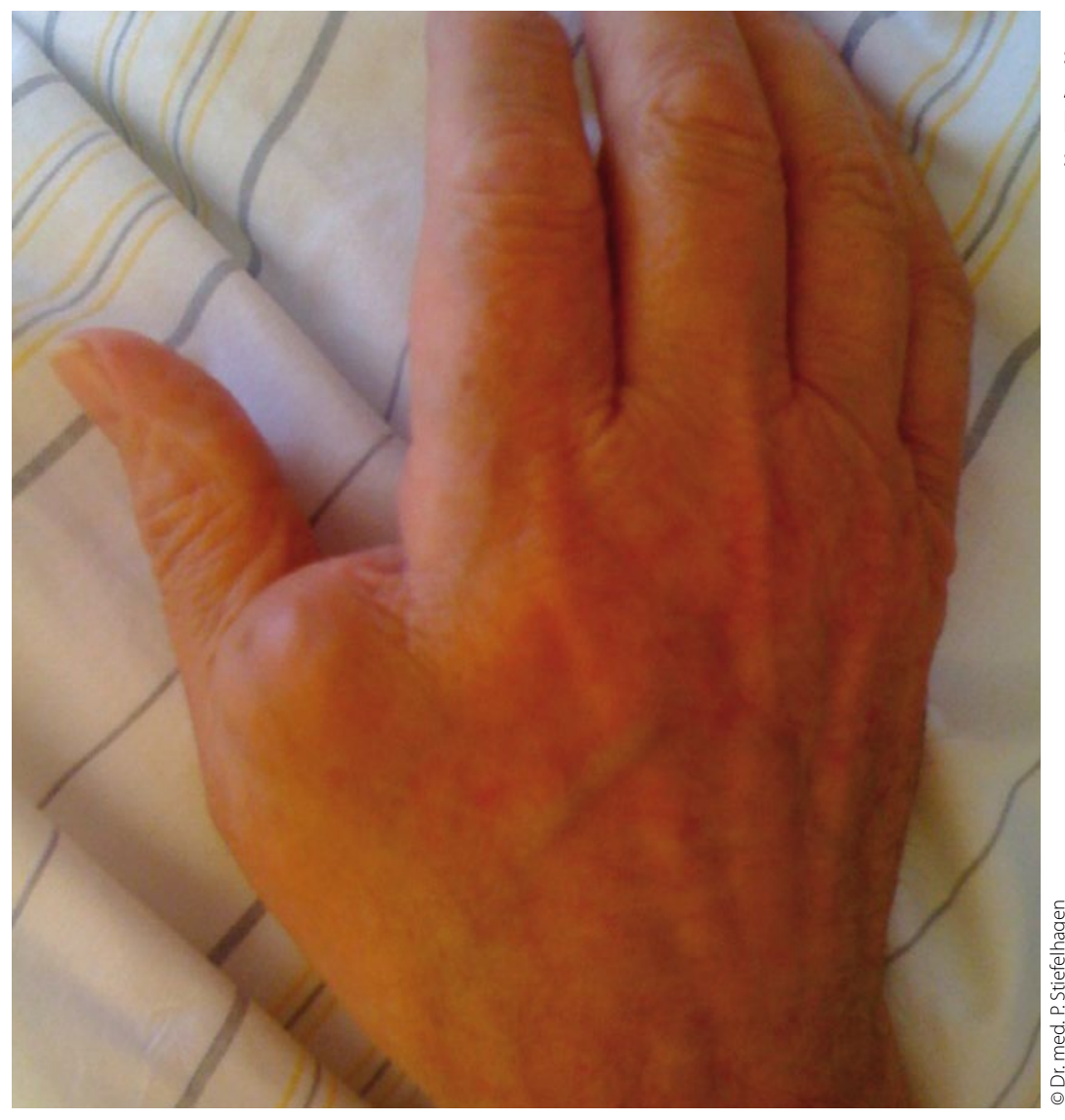

Das Ganglion ist eine Geschwulstbildung infolge Ausstülpung der Gelenkkapsel bzw. des Sehnenscheidengewebes.

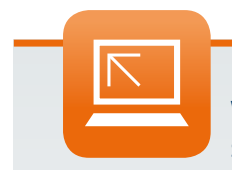

Weitere Infos auf springermedizin.de

Weitere Fälle unserer Leser finden Sie im Internet unter: - www.springermedizin.de/ blickdiagnose 